\title{
Italian Cohort of the Nivolumab EAP in Squamous NSCLC: Efficacy and Safety in Patients With CNS Metastases
}

\author{
DIEGO CORTINOVIS ${ }^{1}$, RITA CHIARI ${ }^{2}$, ANNAMARIA CATINO ${ }^{3}$, FRANCESCO GROSSI ${ }^{4}$, \\ FILIPPO DE MARINIS ${ }^{5}$, FRANCESCA SPERANDI ${ }^{6}$, FRANCOVITO PIANTEDOSI $^{7}$, \\ MILENA VITALI ${ }^{8}$, HECTOR J. SOTO PARRA ${ }^{9}$, MARIA RITA MIGLIORINO ${ }^{10}$, \\ CARLO TONDINI ${ }^{11}$, DAVIDE TASSINARI ${ }^{12}$, ANTONIO FRASSOLDATI ${ }^{13}$, FRANCESCO VERDERAME $^{14}$, \\ ANTONIO PAZZOLA ${ }^{15}$, FRANCESCO COGNETTI ${ }^{16}$, GENNARO PALMIOTTI ${ }^{17}$, PAOLO MARCHETTI ${ }^{18}$, \\ ARMANDO SANTORO ${ }^{19}$, DIANA GIANNARELLI ${ }^{16}$, FRANCESCA COLONESE ${ }^{1}$ and ANGELO DELMONTE ${ }^{20}$ \\ ${ }^{1}$ Medical Oncology/Lung Unit, San Gerardo Hospital, Monza, Italy; \\ ${ }^{2}$ Medical Oncology, Santa Maria della Misericordia Hospital, Perugia, Italy; \\ ${ }^{3}$ National Cancer Research Centre, Giovanni Paolo II Institute, Bari, Italy; \\ ${ }^{4}$ Lung Cancer Unit, San Martino Hospital, Genoa, Italy; ${ }^{5}$ European Institute of Oncology, Milan, Italy; \\ ${ }^{6}$ Sant'Orsola Malpighi Hospital, Bologna, Italy; ${ }^{7}$ Colli - Monaldi Hospital, Naples, Italy; \\ ${ }^{8}$ Foundation IRCCS, National Tumor Institute, Milan, Italy; ${ }^{9}$ Vittorio Emanuele Hospital, Catania, Italy; \\ ${ }^{10}$ San Camillo - Forlanini Hospital, Rome, Italy; ${ }^{11}$ Papa Giovanni XXIII Hospital, Bergamo, Italy; \\ ${ }^{12}$ Romagna University Hospital, Rimini, Italy; ${ }^{13}$ Ferrara University Hospital, Ferrara, Italy; \\ ${ }^{14}$ Villa Sofia-Cervello Hospital, Palermo, Italy; ${ }^{15}$ Sassari Hospital, Sassari, Italy; \\ ${ }^{16}$ Regina Elena National Tumor Institute, Rome, Italy; \\ ${ }^{17}$ Venere Hospital, Bari, Italy; ${ }^{18}$ Sant'Andrea Hospital, Rome, Italy; \\ ${ }^{19}$ Humanitas Cancer Center Milan, Rozzano, Italy; \\ ${ }^{20}$ Romagna Scientific Institute for the Treatment of Tumors, Meldola, Italy
}

\begin{abstract}
Background/Aim: Brain metastases are an additional challenge in patients with non-small-cell lung cancer (NSCLC) because most chemotherapy agents cannot cross the bloodbrain barrier. Nivolumab has demonstrated efficacy in patients with advanced squamous NSCLC, but because patients with central nervous system (CNS) metastases are typically excluded from registration trials, 'field-practice' data are needed. Patients and Methods: Patients in the Italian cohort of the Expanded Access Program (EAP) who had CNS metastases at baseline were analyzed. Results: Thirty-seven patients with CNS metastases received a median of six doses of nivolumab. Three patients (8\%) had grade 3-4 adverse events and one patient discontinued due to an adverse event. The objective response rate was 19\%. Median overall survival was $5.8(95 \%$ confidence interval $=1.9-9.8)$ months and median progressionfree survival was 4.9 (95\% confidence interval=2.7-7.1)
\end{abstract}

Correspondence to: Diego Cortinovis, SC Oncologia Medica/SS Lung Unit, ASST Ospedale San Gerardo, Via Pergolesi 33, 20900 Monza, Italy. Tel: +390392336040, e-mail: d.cortinovis@asst-monza.it

Key Words: Brain metastases, immunotherapy, PD1 inhibitor, realworld evidence. months. Conclusion: The safety and efficacy of nivolumab in patients with CNS metastases appear to be similar to those seen in the overall EAP cohort in Italy.

Squamous non-small-cell lung cancer (NSCLC) is a distinct clinical and pathological subtype of NSCLC, characterized by a high mutation rate and substantial genomic complexity, which may contribute to its poor prognosis (1). Recently, the treatment paradigm for NSCLC has changed with the introduction of immune checkpoint inhibitors (nivolumab, pembrolizumab, and atezolizumab and durvalumab) that block the programmed death-1 (PD-1)/programmed deathligand 1 (PD-L1) pathway and restore the antitumor immune response (2-7).

Nivolumab, a fully human PD1 antibody, has been approved in the USA and the European Union for the treatment of patients with locally advanced or metastatic NSCLC whose disease progresses during or after platinumbased chemotherapy $(8,9)$. Median overall survival (OS) was significantly longer with nivolumab compared to docetaxel in patients who were previously treated for advanced squamous NSCLC in CheckMate 017 [9.2 vs. 6.0 months; hazard ratio for death $=0.59$; $95 \%$ confidence interval $(\mathrm{CI})=0.44-0.79 ; p<0.001](3)$, with 2 -year OS rates 
of $23 \%$ with nivolumab and $8 \%$ with docetaxel $(10,11)$. Comparable results were obtained in CheckMate 057 (4).

The expanded access program (EAP) for nivolumab in advanced NSCLC allowed patients from several countries who were unable to participate in local nivolumab clinical trials to obtain treatment with nivolumab before it became commercially available. Patients with central nervous system (CNS) metastases are commonly excluded from trials. CNS metastases are an adverse prognostic factor, in part because most cytotoxic chemotherapy agents do not readily cross the blood-brain barrier (12). An analysis of preliminary data from the entire Italian cohort of patients with squamous NSCLC enrolled in the nivolumab NSCLC EAP was recently reported (13). Here, we present preliminary data for a subset of these patients who had CNS metastases.

\section{Patients and Methods}

Patients. Eligibility criteria for the EAP were: age $\geq 18$ years; histologically or cytologically confirmed stage IIIB or IV squamous NSCLC; disease progression or disease recurrence during or after $\geq 1$ prior systemic treatments for advanced or metastatic disease; recurrent disease within 6 months after completion of platinumbased chemoradiation for locally advanced disease; Eastern Cooperative Oncology Group (ECOG) performance status $\leq 2$; prior chemotherapy, tyrosine kinase inhibitor treatment, immunotherapy or palliative radiotherapy completed $\geq 2$ weeks before initiation of nivolumab; resolution or stabilization of all adverse events (AEs) prior to baseline; adequate organ function; life expectancy $\geq 6$ weeks; treated metastatic CNS lesions without neurological symptoms related to those lesions for $\geq 2$ weeks before enrolment and no need of corticosteroids or on a stable or a decreasing dose $\leq 10 \mathrm{mg}$ of prednisone daily (or equivalent).

Exclusion criteria were: autoimmune disease (except type 1 diabetes mellitus, residual hypothyroidism due to an autoimmune condition requiring hormone replacement therapy or psoriasis not requiring systemic treatment); HIV infection; carcinomatous meningitis; symptomatic interstitial lung disease; prior therapy with any drug specifically targeting T-cell co-stimulation or checkpoint pathways, or eligibility for another clinical study with nivolumab. All patients provided written, informed consent.

Study design and treatment. Physicians requested nivolumab through the EAP and complied with good clinical practice and ethical standards. The EAP guidelines were approved by the Institutional Review Board at each participating center. Patients received i.v. nivolumab $3 \mathrm{mg} / \mathrm{kg} / 2$ weeks for up to 24 months or until disease progression, unacceptable toxicity, or consent withdrawal. Dose reduction was not allowed, but delayed treatment was permitted in the event of toxicity.

Assessments. There were no pre-specified study endpoints. Safety evaluation: AEs record, physical examination, ECOG performance status, haematology and clinical chemistry tests, and thyroid function tests according to local regulations and standards of care. AEs were graded according to the National Cancer Institute Common Terminology Criteria for Adverse Events version 4.0 (14), and their causal relationship to treatment was determined by
Table I. Patient demographic and baseline characteristics.

\begin{tabular}{|c|c|c|}
\hline Characteristic & $\begin{array}{l}\text { CNS metastases } \\
\quad(\mathrm{n}=37)\end{array}$ & $\begin{array}{l}\text { All patients } \\
(\mathrm{n}=371)\end{array}$ \\
\hline \multicolumn{3}{|l|}{ Gender, n $(\%)$} \\
\hline Male & $24(65)$ & $298(80)$ \\
\hline Female & $13(35)$ & $73(20)$ \\
\hline \multicolumn{3}{|l|}{ Age, years } \\
\hline Median & 64 & 68 \\
\hline Range & $31-77$ & $31-91$ \\
\hline$\geq 75, \mathrm{n}(\%)$ & $1(3)$ & $70(19)$ \\
\hline \multicolumn{3}{|c|}{ Smoking status, n (\%) } \\
\hline Smoker & $11(30)$ & $83(22)$ \\
\hline Former smoker & $18(49)$ & $225(61)$ \\
\hline Never smoker & $5(13)$ & $31(8)$ \\
\hline Unknown & $3(8)$ & $32(9)$ \\
\hline \multicolumn{3}{|l|}{ ECOG PS, n (\%) } \\
\hline 0 & $14(38)$ & $134(36)$ \\
\hline 1 & $22(59)$ & $215(58)$ \\
\hline 2 & $1(3)$ & $22(6)$ \\
\hline \multicolumn{3}{|c|}{ Site of metastasis, $\mathrm{n}(\%)$} \\
\hline CNS & $37(100)$ & $37(10)$ \\
\hline Liver & 7 (19) & $63(17)$ \\
\hline Bone & $16(43)$ & $120(32)$ \\
\hline Other & $29(78)$ & $331(89)$ \\
\hline \multicolumn{3}{|c|}{$\begin{array}{l}\text { Number of prior systemic } \\
\text { therapies, } \mathrm{n}(\%)\end{array}$} \\
\hline 1 & $11(30)$ & $162(44)$ \\
\hline 2 & $18(48)$ & $120(32)$ \\
\hline 3 & $7(19)$ & $68(18)$ \\
\hline$\geq 4$ & $1(3)$ & $21(6)$ \\
\hline
\end{tabular}

CNS: Central nervous system; ECOG: Eastern Cooperative Oncology Group performance status.

the investigators. Efficacy: investigator-assessed objective tumor response, date of disease progression (time from the first drug administration to disease progression or death from any cause), and survival.

Statistical analysis. Patients included in the safety and efficacy analyses received at least one dose of nivolumab. Objective response rate (ORR), disease control rate [DCR; the combined rates of complete response (CR), partial response, and stable disease], progression-free survival (PFS), and OS were evaluated. Median PFS and OS were estimated using the Kaplan-Meier method, with 95\%CIs derived using the asymptotic variance Greenwood method. PFS was calculated as the time between the first nivolumab cycle and evidence of progressive disease (PD) or death.

\section{Results}

Patients and treatment. A total of 371 patients (Table I) were enrolled in the EAP between April and September 2015 at 96 centers in Italy and received at least 1 (median=6, range $=1-22$ ) dose of nivolumab. Median follow-up was 7.1 months (range=0.1-16.4 months). 


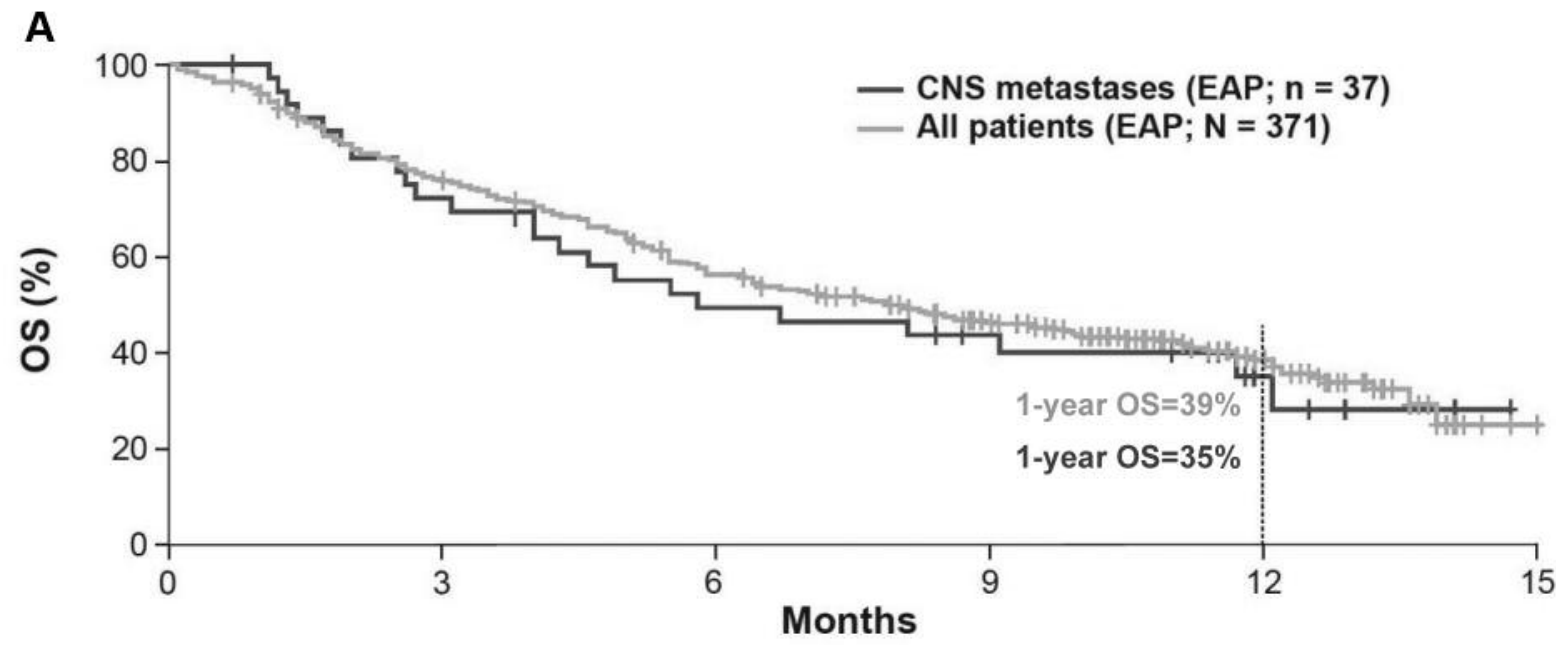

B

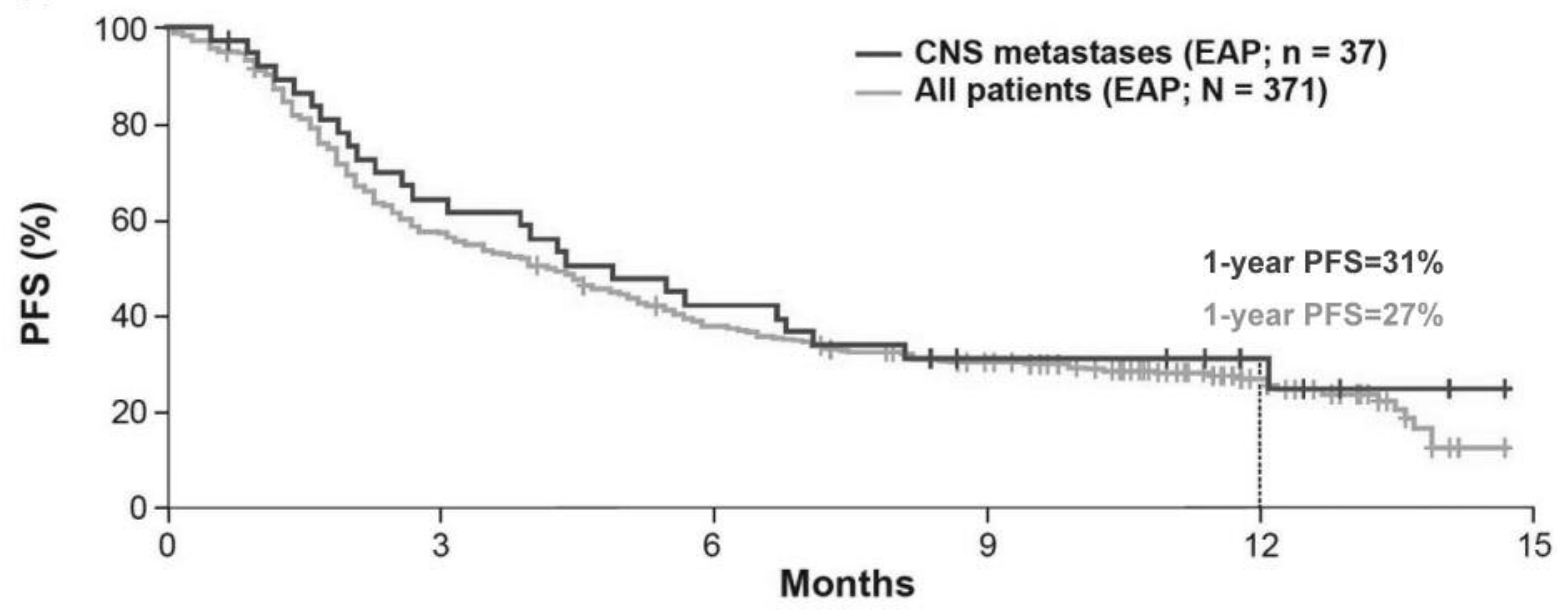

Figure 1. Kaplan-Meier estimates of overall survival (OS; A) and progression-free survival (PFS; B). CNS: Central nervous system; EAP: expanded access program.

CNS metastases were diagnosed in 37/371 (10\%) (Table I). In this subgroup, $22 \%$ had received corticosteroids and $57 \%$ had received prior radiotherapy. Median number of nivolumab doses was 6 (range $=1-18)$, median follow-up 5.5 months (range=0.7-15 months). Six $(16 \%)$ and two $(5 \%)$ patients received concomitant corticosteroids and radiotherapy, respectively, during the EAP for the control of symptoms related to CNS metastases.

At the time of the analysis, nivolumab had been discontinued in 281 patients $(76 \%)$ in the overall population, primarily because of PD $[\mathrm{n}=167(59 \%)]$ or death $[\mathrm{n}=68$ (24\%)]. Among patients with CNS metastases, 33 (89\%) had discontinued nivolumab, mainly for PD [n=18 (55\%)] or death $[n=9(27 \%)]$. Four patients $(11 \%)$ with CNS metastases continued treatment.
Safety. Safety data are reported in Table II. Treatment-related AEs (grade 2 skin reaction and mucositis) led to discontinuation in one/33 (3\%) patients with CNS metastases who discontinued treatment. CNS events (seizure, loss of balance, postural instability, disorientation, and stupor) were reported in five patients (14\%) with CNS metastases; none of these events were grade 3-4 in severity or considered to be treatment-related.

No treatment-related deaths were reported in the overall study population. Treatment-related AEs with a potential immunologicaI aetiology were addressed using protocoldefined toxicity management algorithms. Treatment-related AEs led to discontinuation in $14 / 281$ (5\%) patients in the overall population who discontinued treatment. Efficacy. Efficacy results are reported in Table III. 
Table II. Frequency [n (\%)] of treatment-related adverse events occurring in $\geq 1 \%$ of all patients.

\begin{tabular}{|c|c|c|c|c|}
\hline \multirow[t]{2}{*}{ Category/adverse event } & \multicolumn{2}{|c|}{ CNS metastases $(n=37)$} & \multicolumn{2}{|c|}{ All patients $(\mathrm{N}=371)$} \\
\hline & Any grade & Grade 3-4 & Any grade & Grade 3-4 \\
\hline Any adverse event & $12(32)$ & $3(8)$ & $109(29)$ & $21(6)$ \\
\hline General & $7(19)$ & $1(3)$ & $34(9)$ & $2(1)$ \\
\hline Fatigue/asthenia & $6(16)$ & $1(3)$ & $24(6)$ & $2(1)$ \\
\hline Pyrexia & 0 & 0 & $10(3)$ & 0 \\
\hline Lack of appetite/anorexia & $2(5)$ & 0 & $9(2)$ & 0 \\
\hline Skin and mucosal & $5(14)$ & $2(5)$ & $42(11)$ & $5(1)$ \\
\hline Rash & $3(8)$ & $1(3)$ & $31(8)$ & $3(1)$ \\
\hline Gastrointestinal & $1(3)$ & 0 & $27(7)$ & $4(1)$ \\
\hline Diarrhoea & 0 & 0 & $18(5)$ & $4(1)$ \\
\hline Pain & 0 & 0 & $19(5)$ & $3(1)$ \\
\hline Endocrine & 0 & 0 & $16(4)$ & $1(<1)$ \\
\hline Hypothyroidism & 0 & 0 & $10(3)$ & 0 \\
\hline Hyperthyroidism & 0 & 0 & $5(1)$ & $1(<1)$ \\
\hline Respiratory/pulmonary & 0 & 0 & $12(3)$ & $4(1)$ \\
\hline Pneumonitis & 0 & 0 & $3(1)$ & $1(<1)$ \\
\hline Haematological & 0 & 0 & $10(3)$ & $1(<1)$ \\
\hline Anaemia & 0 & 0 & $9(2)$ & $1(<1)$ \\
\hline Hepatic/pancreatic & 0 & 0 & $8(2)$ & $4(1)$ \\
\hline Transaminase increase & 0 & 0 & $6(2)$ & $4(1)$ \\
\hline Lipase/amylase increase & 0 & 0 & $2(1)$ & 0 \\
\hline
\end{tabular}

CNS: Central nervous system.

Table III. Response to treatment.

\begin{tabular}{|c|c|c|c|c|}
\hline \multirow[t]{2}{*}{ Tumour response } & \multicolumn{2}{|c|}{ CNS metastases $(n=37)$} & \multicolumn{2}{|c|}{ All patients $(n=371)$} \\
\hline & First assessment, $\mathrm{n}(\%)$ & Best response, $\mathrm{n}(\%)$ & First assessment, n (\%) & Best response, $\mathrm{n}(\%)$ \\
\hline Objective response rate & $7(19)$ & $7(19)$ & $51(14)$ & $67(18)$ \\
\hline Disease control rate ${ }^{\mathrm{a}}$ & $18(49)$ & $18(49)$ & $151(41)$ & $175(47)$ \\
\hline \multicolumn{5}{|l|}{ Best response } \\
\hline Complete response & 0 & $1(3)$ & $1(<1)$ & $4(1)$ \\
\hline Partial response & $7(19)$ & $6(16)$ & $50(13)$ & $63(17)$ \\
\hline Stable disease & $11(30)$ & $11(30)$ & $100(27)$ & $108(29)$ \\
\hline Progressive disease & $19(51)$ & $19(51)$ & $212(57)$ & $189(51)$ \\
\hline Could not be determined & 0 & 0 & $8(2)$ & $7(2)$ \\
\hline
\end{tabular}

aDefined as the combined rate of complete response, partial response, and stable disease.

The OS rate at 1 year was $35 \%$ for patients with CNS metastases and $39 \%$ for the overall population (Figure 1A). Median OS was $5.8(95 \% \mathrm{CI}=1.8-9.8)$ months for patients with CNS metastases and $7.9(95 \% \mathrm{CI}=6.2-9.6)$ months for the overall population.

The PFS rate at 1 year was $31 \%$ for patients with CNS metastases and $27 \%$ for the overall population (Figure 1B). The median PFS was $4.9(95 \% \mathrm{CI}=2.7-7.1)$ months for patients with CNS metastases and 4.2 (95\% CI=3.4-5.0) months for the overall population.

\section{Discussion}

Nivolumab was well tolerated in patients with squamous NSCLC and CNS metastases from the Italian EAP cohort, and the safety profile appeared to be similar to that of the overall EAP population. The frequency of grade 3-4 treatment-related AEs was comparable in patients with CNS metastases $(8 \%)$ and in the overall EAP population $(6 \%)$. The percentage of patients who discontinued nivolumab treatment because of a treatment-related $\mathrm{AE}$ was $3 \%$ in the 
subgroup with CNS metastases and 5\% in the overall EAP population.

Efficacy with nivolumab in the subset of EAP patients with CNS metastases appeared to be similar to that observed in the overall EAP population: the 1-year OS rates were $35 \%$ and $39 \%$, respectively, and the 1-year PFS rates were $31 \%$ and $27 \%$, respectively.

Some limitations of this study should be considered: possible patient selection bias and inconsistencies in assessment timing, absence of formal and specific radiological assessment, the small patient number and exclusion of patients with symptomatic CNS metastases, PD-L1 expression was not detected.

Our data were consistent with results reported for the nivolumab arm of CheckMate 017 (3), where the 12-month OS rate was $42 \%$ and 1-year PFS rate was $21 \%$. Grade 3-4 treatment-related AEs occurred in $7 \%$ of patients in the nivolumab arm, and $3 \%$ of patients discontinued the drug because of a treatment-related $\mathrm{AE}$.

Response in CNS lesions have been reported in clinical trials and in case reviews, in patients treated with nivolumab alone or in combination with other therapies (2, 15). Based on encouraging results, the Radiation Therapy Oncology Group has begun a randomized phase III study, RTOG 3505, to evaluate post-chemoradiation nivolumab compared to placebo in patients with unresectable stage 3 NSCLC (16).

Cases of pseudo-progression (an apparent tumor size increase, possibly due to lymphocyte infiltration) with nivolumab in lung cancer have been reported (17), and physicians must make decisions about continuing or discontinuing nivolumab for disease progression based on their assessment of the risks and potential benefits.

\section{Conflicts of Interest}

LC received fees for speakers' bureau participation from AstraZeneca, Bristol-Myers Squibb, and Novartis. DG received fees for speakers' bureau participation from Boehringer Ingelheim and Lilly, and travel, accommodation, and expenses from Bristol-Myers Squibb. AA received honoraria from Boehringer Ingelheim, BristolMyers Squibb, and Lilly, and served in a consulting/advisory role for Boehringer Ingelheim, Bristol-Myers Squibb, GlaxoSmithKline, Lilly, and MSD Oncology. DC received honoraria from Roche, MSD, Boehringer Ingrlheim and served in a consulting/advisory for MSD, BMS, Boehirnger Ingelheim, AZ. FG received honoraria from Bristol-Myers Squibb, MSD, AstraZeneca, Roche and served in a consulting/advisory role for Boehringer Ingelheim, BristolMyers Squibb, MSD, Roche, Pierre Fabre, Astra Zeneca. MRM received Honoraria /advisory role from Boehringer Ingelheim, Bristol-Myers Squibb, AstraZeneca, Pfizer.

\section{Funding}

Bristol-Myers Squibb, Inc.

\section{Authors' Contributions}

All Authors contributed to the drafting of and making the decision to submit the article for publication. All remaining Authors have no relationships to disclose.

\section{Nivolumab Expanded Access Program in Squamous NSCLC: Investigators in Italy}

Mario Airoldi, Città della Salute e della Scienza di Torino, Torino; Oscar Alabiso, Azienda Ospedaliero Universitaria Maggiore della Carità di Novara, Novara; Giuseppe Altavilla, Policlinico di Messina, Messina; Paola Antonelli, Ospedale di Busto Arsizio, Busto Arsizio; Antonio Ardizzoia, Ospedale Alessandro Manzoni, Lecco; Andrea Ardizzoni, Policlinico Sant'Orsola-Malpighi, Bologna; Salvatore Artale, Azienda Ospedaliero Sant'Antonio Abate di Gallarate, Gallarate; Fabrizio Artioli, Ospedale di Carpi, Carpi; Editta Baldini, Azienda USL 2 Lucca, Lucca; Carmelo Bengala, Ospedale di Grosseto, Grosseto; Antonio Bernardo, Fondazione Maugeri, Pavia; Alessandro Bertolini, Azienda Ospedaliera Valtellina e Valchiavenna, Sondrio; Paolo Bidoli, Ospedale San Gerardo, Monza; Sergio Bracarda, Azienda USL 8, Arezzo; Alba Brandes, Ospedale di Bellaria, Bologna; Emilio Bria, Università degli Studi di Verona, Verona; Luana Calabrò, Policlinico Le Scotte, Siena; Giacomo Cartenì, Azienda Ospedaliera di Rilievo Nazionale Antonio Cardarelli, Napoli; Fausto Barbieri, Azienda Ospedaliero Universitaria di Modena, Modena; Federico Cappuzzo, Presidio Ospedaliero di Livorno, Livorno; Luigi Cavanna, Ospedale Guglielmo da Saliceto, Piacenza; Antonio Chella, Azienda Ospedaliero Universitaria Pisana, Pisa; Fortunato Ciardiello, Seconda Università degli Studi di Napoli, Napoli; Saverio Cinieri, Presidio Ospedaliero Antonio Perrino, Brindisi; Libero Ciuffreda, Città della Salute e della Scienza di Torino, Torino; Mario Alberto Clerico, Ospedale degli Infermi, Biella; Francesco Cognetti, Istituto Nazionale Tumori Regina Elena, Roma; Pier Franco Conte, Istituto Oncologico Veneto, Padova; Enrico Cortesi, Policlinico Umberto I, Roma; Lucio Crinò, Azienda Ospedaliero Perugia , Perugia; Domenico Cristiano Corsi, Ospedale Fatebenefratelli San Giovanni Calibita, Roma; Andrea De Censi, Ospedali Galliera, Genova; Filippo De Marinis, Istituto Europeo di Oncologia, Milano; Elvira De Marino, Ospedale Sant'Andrea, Vercelli; Sabino De Placido, Azienda Ospedaliero Universitaria Federico II, Napoli; Alessandro Del Conte, Azienda Ospedaliero Santa Maria degli Angeli, Pordenone; Angelo Delmonte; Istituto Scientifico Romagnolo per lo Studio e la Cura dei Tumori, Meldola; Francesco Di Costanzo, Azienda Ospedaliero Universitaria Careggi, Firenze; Angelo Di Leo, AUSL4 - Nuovo Ospedale di Prato - Santo Stefano, Prato; Marco Di Lieto, Azienda USL 3 di Pistoia, Pistoia; Liberato Di Lullo, Presidio Ospedaliero F. Veneziale, Isernia; Daniele Fagnani, Azienda SocioSanitaria Territoriale di Vimercate, Vimercate; Alfredo Falcone, Azienda Ospedaliero Universitaria Pisana Spedali Riuniti di Santa Chiara, Pisa; Gabriella Farina, Ospedale Fatebenefratelli, Milano; Gianpiero Fasola, Azienda Ospedaliero Universitaria Santa Maria della Misericordia, Udine; Francesco Ferraù, Ospedale San Vincenzo, Taormina; Luisa Fioretto, Ospedale Santa Maria Annunziata, Bagno a Ripoli; Paolo Foa, Azienda Ospedaliero San Paolo, Milano; Guido Francini, Policlinico Le Scotte , Siena; Antonio Frassoldati, Arcispedale Santa Anna, Ferrara; Domenico Galetta, Istituto Tumori Giovanni Paolo II, Bari; Marco Galliano, 
Ospedale Acqui Terme, Aqui Terme; Teresa Gamucci, Presidio Ospedaliero SS Trinità, Sora; Marina Garassino, Istituto Nazionale Tumori, Milano; Luca Gianni, Ospedale San Raffaele, Milano; Carmelo Giannitto, Ospedale Gravina e Santo Pietro, Caltagirone; Lucio Giustini, Ospedale di Fermo, Fermo; Cesare Gridelli, Azienda Ospedaliero San Giuseppe Moscati, Avellino; Francesco Grossi, Azienda Ospedaliero Universitaria San Martino - Istituto Nazionale per la Ricerca sul Cancro, Genova; Alfonso Illiano, Azienda Ospedaliero dei Colli, Napoli; Lorenzo Livi, Azienda Ospedaliero Universitaria Careggi, Firenze; Paolo Marchetti, Ospedale Sant'Andrea , Roma; Maria Rita Migliorino, San Camillo Forlanini, Roma; Enrico Mini, Azienda Ospedaliero Universitaria Careggi, Firenze; Vincenzo Montesarchio, Azienda Ospedaliero dei Colli, Napoli; Alessandro Morabito, Istituto Pascale, Napoli; Alessandro Mozzicafreddo, Ospedale Umberto Parini, Aosta; Donato Natale, Ospedale Santo Spirito, Pescara; Gianmauro Numico, Azienda Ospidaliera Nazionale SS Antonio e Biagio e Cesare Arrigo, Alessandria; Gennaro Palmiotti, Ospedale di Venere, Bari; Lorenzo Pavesi, Fondazione Maugeri, Pavia; Antonio Pazzola, Ospedale Civile SS Annunziata, Sassari; Paolo Pedrazzoli, Policlinico San Matteo, Pavia; Francovito Piantedosi, Azienda Ospedaliero dei Colli, Napoli; Graziella Pinotti, Ospedale di Circolo e Fondazione Macchi, Varese; Carmine Pinto, Arcispedale Santa Maria Nuova di Reggio Emilia, Reggio Emilia; Fausto Roila, Azienda Ospedaliero Santa Maria, Terni; Enzo Maria Ruggeri, Ospedale Belcolle, Viterbo; Antonio Santo, Gruppo Interdisciplinare Veronese Oncologia Polmonare - Azienda Ospedaliero Universitaria Integrata di Verona, Verona; Armando Santoro, Istituto Clinico Humanitas, Milano; Maria Giuseppina Sarobba, ASL3 Nuoro San Francesco, Nuoro; Alessandro Scoppola, Istituto Dermopatico dell'Immacolata, Roma; Salvatore Siena, Niguarda cancer Center Ospedale Niguarda ca' Granda, Milano; Rosa Rita Silva, Azienda Sanitaria Unica Regionale Marche, Fabriano; Hector Soto Parra, Azienda Ospedaliero Universitaria Policlinico Vittorio Emanuele, Catania; Giammarco Surico, Ospedale Vito Fazzi, Lecce; Pierosandro Tagliaferri, Policlinico Mater Domini Germaneto, Catanzaro; Davide Tassinari, Ospedale Rimini, Rimini; Natale Tedde, Presidio Ospedale di Olbia, Olbia; Marcello Tiseo, Azienda Ospedaliero Universitaria di Parma, Parma; Carlo Tondini, Ospedale Papa Giovanni XXIII, Bergamo; Giuseppe Tonini, Campus Biomedico, Roma; Marco Tucci, Policlinico di Bari, Bari; Daniele Turci, Ospedale S. Maria delle Croci, Ravenna; Francesco Verderame, Azienda Ospedaliera "Villa Sofia - Cervello," Palermo;; Guido Vietti Ramus, Ospedale San Giovanni Bosco, Torino.

\section{Acknowledgements}

The Authors thank the patients and their families who made this EAP possible, as well as the clinical study teams who were involved in this program. Professional medical writing and editorial assistance was provided by William Watkins of StemScientific, funded by Bristol-Myers Squibb. Editorial assistance was provided by Luca Giacomelli, Ph.D., Laura Brogelli, and Aashni Shah (Polistudium srl.), supported by internal funds.

\section{References}

1 Socinski MA, Obasaju C, Gandara D, Hirsch FR, Bonomi P, Bunn P, Kim ES, Langer CJ, Natale RB, Novello S, Paz-Ares L, Pérol M, Reck M, Ramalingam SS, Reynolds CH, Spigel DR, Stinchcombe TE, Wakelee $\mathrm{H}$, Mayo $\mathrm{C}$ and Thatcher $\mathrm{N}$ :
Clinicopathologic features of advanced squamous NSCLC: J Thorac Oncol 11(9): 1411-1422, 2016. PMID: 27296106. DOI: 10.1016/j.jtho.2016.05.024

2 Rizvi NA, Mazières J, Planchard D, Stinchcombe TE, Dy GK, Antonia SJ, Horn L, Lena H, Minenza E, Mennecier B, Otterson GA, Campos LT, Gandara DR, Levy BP, Nair SG, Zalcman G, Wolf J, Souquet PJ, Baldini E, Cappuzzo F, Chouaid C, Dowlati A, Sanborn R, Lopez-Chavez A, Grohe C, Huber RM, Harbison CT, Baudelet C, Lestini BJ and Ramalingam SS: Activity and safety of nivolumab, an anti-PD-1 immune checkpoint inhibitor, for patients with advanced, refractory squamous non-small-cell lung cancer (CheckMate 063): A phase 2, single-arm trial. Lancet Oncol 16(3): 257-265, 2015. PMID: 25704439. DOI: 10.1016/S1470-2045(15)70054-9

3 Brahmer J, Reckamp KL, Baas P, Crinò L, Eberhardt WE, Poddubskaya E, Antonia S, Pluzanski A, Vokes EE, Holgado E, Waterhouse D, Ready N, Gainor J, Arén Frontera O, Havel L, Steins M, Garassino MC, Aerts JG, Domine M, Paz-Ares L, Reck M, Baudelet C, Harbison CT, Lestini B and Spigel DR: Nivolumab versus docetaxel in advanced squamous-cell nonsmall-cell lung cancer. N Engl J Med 373(2): 123-135, 2015. PMID: 26028407. DOI: 10.1056/NEJMoa1504627

4 Borghaei H, Paz-Ares L, Horn L, Spigel DR, Steins M, Ready NE, Chow LQ, Vokes EE, Felip E, Holgado E, Barlesi F, Kohlhäufl M, Arrieta O, Burgio MA, Fayette J, Lena H, Poddubskaya E, Gerber DE, Gettinger SN, Rudin CM, Rizvi N, Crinò L, Blumenschein GR Jr., Antonia SJ, Dorange C, Harbison $\mathrm{CT}$, Graf Finckenstein F and Brahmer JR: Nivolumab versus docetaxel in advanced nonsquamous non-small-cell lung cancer. N Engl J Med 373(17): 1627-1639, 2015. PMID: 26412456. DOI: 10.1056/NEJMoa1507643

5 Herbst RS, Baas P, Kim DW, Felip E, Pérez-Gracia JL, Han JY, Molina J, Kim JH, Arvis CD, Ahn MJ, Majem M, Fidler MJ, de Castro G Jr., Garrido M, Lubiniecki GM, Shentu Y, Im E, Dolled-Filhart $\mathrm{M}$ and Garon $\mathrm{EB}$ : Pembrolizumab versus docetaxel for previously treated, PD-L1-positive, advanced nonsmall-cell lung cancer (KEYNOTE-010): A randomised controlled trial. Lancet 387(10027): 1540-1550, 2016. PMID: 26712084. DOI: 10.1016/S0140-6736(15)01281-7

6 Rittmeyer A, Barlesi F, Waterkamp D, Park K, Ciardiello F, von Pawel J, Gadgeel SM, Hida T, Kowalski DM, Dols MC, Cortinovis DL, Leach J, Polikoff J, Barrios C, Kabbinavar F, Frontera OA, De Marinis F, Turna H, Lee JS, Ballinger M, Kowanetz M, He P, Chen DS, Sandler A, Gandara DR and OAK Study Group: Atezolizumab versus docetaxel in patients with previously treated non-small-cell lung cancer (OAK): A phase 3 , open-label, multicentre randomised controlled trial. Lancet 389(10066): 255-265, 2017. PMID: 27979383. DOI: 10.1016/ S0140-6736(16)32517-X

7 Garassino MC, Cho BC, Kim JH, Mazières J, Vansteenkiste J, Lena H, Corral Jaime J, Gray JE, Powderly J, Chouaid C, Bidoli P, Wheatley-Price P, Park K, Soo RA, Huang Y, Wadsworth C, Dennis PA, Rizvi NA and ATLANTIC Investigators: Durvalumab as third-line or later treatment for advanced non-small-cell lung cancer (ATLANTIC): an openlabel, single-arm, phase 2 study. Lancet Oncol 19(4): 521-536, 2018. PMID: 29545095. DOI: 10.1016/S1470-2045(18)30144$\mathrm{X}$

8 OPDIVO $^{\circledR}$ (nivolumab) (package insert). Princeton, NJ: BristolMyers Squibb Company; February 2017. 
9 Opdivo EMA SmPC: Available at http://www.ema.europa.eu/ docs/en_GB/document_library/EPAR_-_Product_Information/ human/003985/WC500189765.pdf (Accessed 13 June 2017).

10 Horn L, Spigel DR, Vokes EE, Holgado E, Ready N, Steins M, Poddubskaya E, Borghaei H, Felip E, Paz-Ares L, Pluzanski A, Reckamp KL, Burgio MA, Kohlhäeufl M, Waterhouse D, Barlesi F, Antonia S, Arrieta O, Fayette J, Crinò L, Rizvi N, Reck M, Hellmann MD, Geese WJ, Li A, Blackwood-Chirchir A, Healey $\mathrm{D}$, Brahmer $\mathrm{J}$ and Eberhardt WEE: Nivolumab versus docetaxel in previously treated patients with advanced non-small-cell lung cancer: Two-year outcomes from two randomized, open-label, phase III trials (CheckMate 017 and CheckMate 057). J Clin Oncol 35(35): 3924-3933, 2017. PMID: 29023213. DOI: 10.1200/JCO.2017.74.3062

11 Vokes EE, Ready N, Felip E, Horn L, Burgio MA, Antonia SJ, Arén Frontera O, Gettinger S, Holgado E, Spigel D, Waterhouse D, Domine M, Garassino M, Chow LQM, Blumenschein G Jr, Barlesi F, Coudert B, Gainor J, Arrieta O, Brahmer J, Butts C, Steins M, Geese WJ, Li A, Healey D and Crinò L: Nivolumab versus docetaxel in previously treated advanced non-small-cell lung cancer (CheckMate 017 and CheckMate 057): 3-Year update and outcomes in patients with liver metastases. Ann Oncol 29(4): 959-965, 2018. PMID: 29408986. DOI: 10.1093/ annonc/mdy041

12 Owen S and Souhami L: The management of brain metastases in non-small cell lung cancer. Front Oncol 4: 248, 2014. PMID: 25309873. DOI: $10.3389 /$ fonc.2014.00248

13 Crinò L, Bronte G, Bidoli P, Cravero P, Minenza E, Cortesi E, Garassino MC, Proto C, Cappuzzo F, Grossi F, Tonini G, Sarobba MG, Pinotti G, Numico G, Samaritani R, Ciuffreda L, Frassoldati A, Bregni M, Santo A, Piantedosi F, Illiano A, De Marinis F, Tamberi S, Giannarelli D and Delmonte A: Nivolumab and brain metastases in patients with advanced nonsquamous non-small cell lung cancer. Lung Cancer 129: 35-40, 2019. PMID: 30797489. DOI: 10.1016/j.lungcan.2018.12.025
14 National Cancer Institute Common Terminology Criteria for Adverse Events version 4.03. Available at: https://evs.nci. nih.gov/ftp1/CTCAE/CTCAE_4.03/ (Accessed 24 April 2019).

15 Dudnik E, Yust-Katz S, Nechushtan H, Goldstein DA, Zer A, Flex D, Siegal $\mathrm{T}$ and Peled $\mathrm{N}$ : Intracranial response to nivolumab in NSCLC patients with untreated or progressing CNS metastases. Lung Cancer 98: 114-117, 2016. PMID: 27393516. DOI: 10.1016/j.lungcan.2016.05.031

16 Gerber DE, Urbanic JJ, Langer CJ, Hu C, Chang I-F, Lu B, Movsas B, Jeraj R, Curran WJ and Bradley JD: Randomized phase III trial of concurrent chemoradiation followed by nivolumab or placebo for locally advanced non-small cell lung cancer (NSCLC) (RTOG 3505) (abstract TPS8579). J Clin Oncol 35(Suppl), 2017. DOI: 10.1200/JCO.2017.35.15_suppl.TPS8579

17 Tanizaki J, Hayashi H, Kimura M, Tanaka K, Takeda M, Shimizu S, Ito A and Nakagawa K: Report of two cases of pseudoprogression in patients with non-small cell lung cancer treated with nivolumab-including histological analysis of one case after tumor regression. Lung Cancer 102: 44-48, 2016. PMID: 27987588. DOI: 10.1016/j.lungcan.2016.10.014
Received May 28, 2019

Revised June 20, 2019

Accepted June 21, 2019 